\title{
Differential expression of high molecular weight caldesmon in colorectal pericryptal fibroblasts and tumour stroma
}

\author{
H Nakayama, E Miyazaki, H Enzan
}

\begin{abstract}
Aim-To investigate an extent of smooth muscle differentiation of pericryptal fibroblasts.

Methods-Expression of high molecular weight caldesmon $(h-C D)$ and $\alpha$ smooth muscle actin was investigated in 123 invasive colorectal adenocarcinomas and their surrounding non-neoplastic tissues.

Results-The monoclonal antibody to $h$-CD, which showed predominantly positive immunostaining in well differentiated smooth muscle cells, recognised pericryptal fibroblasts, smooth muscle cells, and pericytes, but was not reactive to myofibroblasts. Antibody to $\alpha$ smooth muscle actin recognised not only pericryptal fibroblasts, smooth muscle cells, and pericytes but also myofibroblasts.

Conclusions-Pericryptal fibroblasts show greater smooth muscle differentiation than myofibroblasts and there is a possibility that they are well differentiated smooth muscle cells; $\boldsymbol{h}$-CD is an excellent marker to discriminate pericryptal fibroblasts from myofibroblasts.

(F Clin Pathol 1999;52:785-786)
\end{abstract}

Keywords: high molecular weight caldesmon; pericryptal fibroblast; colon; rectum

Pericryptal fibroblasts play an important role in the progression of colorectal epithelial neoplasms and non-neoplastic disorders. ${ }^{1-3}$ It is 14 May 1999

A

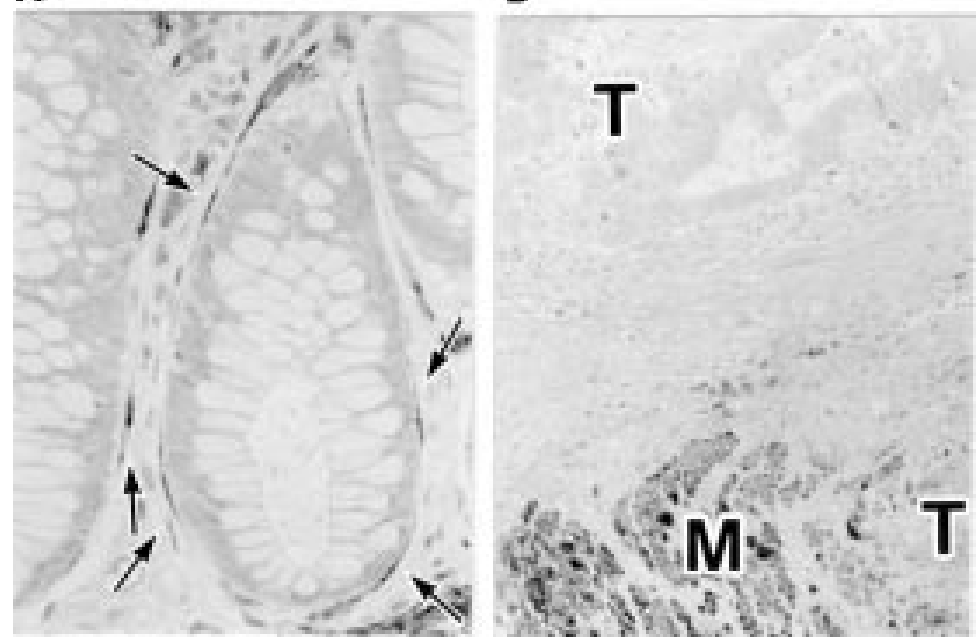

Figure 1 The representative case of immunostaining for high molecular weight caldesmon (h-CD) in colorectal normal and carcinoma tissues. (A) Pericryptal fibroblasts (arrows) are positive for $h-C D$. (B) Myofibroblasts in the desmoplastic stroma are negative for $h-C D$. T, carcinoma; $M$, muscularis propria. suggested that myofibroblasts in the stroma of colorectal carcinomas originate mainly from pericryptal fibroblasts. ${ }^{4}$ However, there have been no reports on the relation between pericryptal fibroblasts and myofibroblasts in the colon and rectum. To investigate the extent of smooth muscle differentiation in pericryptal fibroblasts, we examined expression of two smooth muscle markers, high molecular weight caldesmon $(h-\mathrm{CD})$ and $\alpha$ smooth muscle actin, in colorectal mucosa.

\section{Methods}

We examined 123 surgically resected primary colorectal adenocarcinomas and their adjacent tissues. The monoclonal antibodies used were clone h-CD (Dakopatts) which recognises $h$-CD, and clone 1A4 (Dakopatts) which reacts with $\alpha$ smooth muscle actin. Immunohistochemical studies were performed by the streptavidin-biotin method using the Histofine SAB-PO(M) kit (Nichirei). In the present immunohistochemical study for $h$-CD, deparaffinised tissue sections in $10 \mathrm{mM}$ citrate buffer (pH 6.0) received heat treatment in a microwave oven for 15 minutes before the primary antibody reaction. The antibody against $h$-CD was diluted to $1: 50$.

\section{Results}

In all the cases examined, $h$-CD was positive in pericryptal fibroblasts in the adjacent mucosa (fig 1A) and also positive for vascular smooth muscle cells, smooth muscle cells of muscularis mucosa and muscularis propria, and pericytes, but was negative in myofibroblasts in the desmoplastic tumour stroma (fig 1B); no $h$-CD positive cells were detected except smooth muscle cells and pericytes. In contrast, $\alpha$ smooth muscle actin was positive not only in pericryptal fibroblasts (fig 2A), vascular smooth muscle cells, smooth muscle cells of muscularis mucosa and muscularis propria (parenchymal smooth muscle cells), and pericytes, but also in myofibroblasts (fig 2B). The remaining stromal spindle cells were negative for $h$-CD and $\alpha$ smooth muscle actin. (Note: figs $1 \mathrm{~A}$ and $2 \mathrm{~A}$, and $1 \mathrm{~B}$ and $2 \mathrm{~B}$ are from the same respective sites.)

\section{Discussion}

Pericryptal fibroblasts decrease in number in the sequence: adenoma, intramucosal carcinoma, submucosal invasive adenocarcinoma. ${ }^{1}$ In ulcerative colitis, dysplastic epithelium transforms into adenocarcinoma, and pericryptal fibroblasts decrease in number. ${ }^{3}$ On the 
A

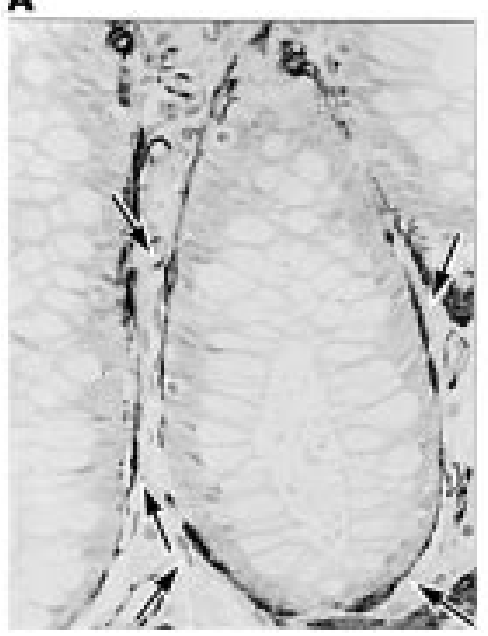

Figure 2 The representative case of immunostaining for a smooth muscle actin (ASMA) in colorectal normal and carcinoma tissues. (A) Pericryptal fibroblasts (arrows) are positive for ASMA. (B) Myofibroblasts in the desmoplastic stroma are also positive. T, carcinoma; $M$, muscularis propria.
B

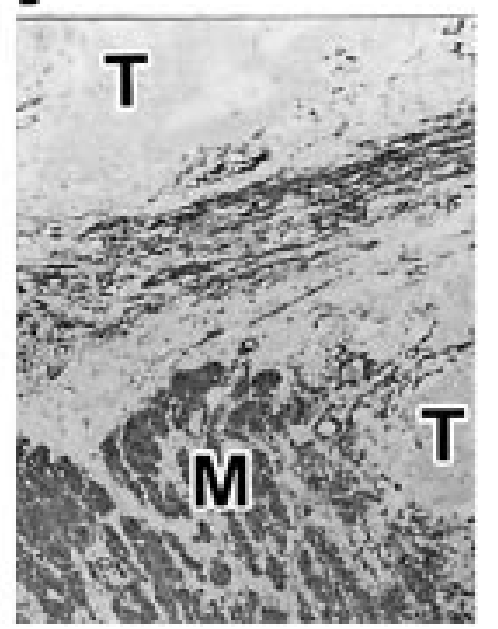

with smooth muscle contraction and localised exclusively in smooth muscle cells ${ }^{7}$; the other caldesmon, low molecular weight caldesmon (MW 77-80 kDa), is also detected in myofibroblasts and non-muscle cells. ${ }^{8}$

In this journal about 12 years ago, ${ }^{9}$ a monoclonal antibody PR2D3 was described, which reacted with the cell membrane of pericryptal fibroblasts, smooth muscle cells throughout the body, and myofibroblasts in Wharton's jelly (myofibroblasts in the desmoplastic stroma of carcinomas were not examined); it did not react with fibroblasts or with cardiac and striated muscle cells. The protein which the antibody recognised was of $140 \mathrm{kDa}$ molecular weight. ${ }^{9}$ There is a possibility that this $140 \mathrm{kDa}$ protein is identical to $h$-CD.

These data, and our present study, suggest that pericryptal fibroblasts share a common differentiation process with vascular and parenchymal smooth muscle cells and that they are more akin to differentiated smooth muscle cells than to myofibroblasts.

In conclusion, our findings indicate that $h$-CD is an excellent marker for pericryptal fibroblasts, and there is a possibility that these cells are in fact well differentiated smooth muscle cells.

fibroblasts ${ }^{4}$ In the previous studies concernin pericryptal fibroblasts, clone $1 \mathrm{~A} 4$ and HHF-35 were used for a marker for pericryptal fibroblasts ${ }^{1-3}$; the latter clone recognises muscle specific but not smooth muscle specific actin. Furthermore, these two antibodies unfortunately react not only with pericryptal fibroblasts but also with myofibroblasts, smooth muscle cells, and pericytes. To detect pericryptal fibroblasts more precisely, another novel marker should be used. In our previous study concerning myofibroblasts at the tumour border of colorectal adenocarcinomas, we performed immunostaining for $\alpha$ smooth muscle actin and $h$-CD in colorectal carcinomas, in order to differentiate myofibroblasts from smooth muscle cells objectively-because myofibroblasts expressed $\alpha$ smooth muscle actin and not $h$-CD, whereas smooth muscle cells were positive for both $\alpha$ smooth muscle actin and $h$-CD. ${ }^{5} 6$

Caldesmon was originally purified from gizzard smooth muscle as a major calmodulin binding protein which also interacts with actin filaments. ${ }^{7}$ Two molecular weight forms of caldesmon are distributed in a wide range of tissues and cells. ${ }^{8}$ It is reported that $h$-CD, molecular weight $120-150 \mathrm{kDa}$, is associated

This work was supported by Foundation for Promotion of Cancer Research in Japan.

1 Yao T, Tsuneyoshi M. Significance of colonic pericryptal fibroblasts in colorectal epithelial tumors. Hum Pathol 1993;24:525-33.

2 Yao T, Tada S, Tsuneyoshi M. Colorectal counterpart of gastric depressed adenoma. A comparison with flat and polypoid adenomas with special reference to the development of pericryptal fibroblasts. Am 7 Surg Pathol 1994;18: ment of per

3 Yao T, Talbot IC. The demonstration of pericryptal fibroblasts in background mucosa and dysplasia complicating ulcerative colitis. Histopathology 1996;28:325-31.

4 Sappino AP, Dietrich PY, Skalli O, et al. Colonic pericryptal Sappino AP, Dietrich PY, Skalli O, et al. Colonic pericryptal
fibroblasts: differentiation pattern in embryogenesis and phenotypic modulation in epithelial proliferative lesions. Virchows Arch A Pathol Anat 1989;415:551-7.

5 Lazard D, Sastre X, Frid MG, et al. Expression of smooth muscle-specific proteins in myoepithelium and stromal myofibroblasts of normal and malignant human breast tissue. Proc Natl Acad Sci USA 1993;90:999-1003.

6 Nakayama H, Enzan H, Miyazaki E, et al. The role of myofibroblasts at the tumor border of invasive colorectal adenocarcinomas. Fpn f Clin Oncol 1998;28:615-20.

7 Sobue K, Muramoto Y, Fujita M, et al. Purification of a calmodulin-binding protein from chicken gizzard that interacts with F-actin. Proc Natl Acad Sci USA 1981;78: 5652-6.

8 Ueki N, Sobue K, Kanda K, et al. Expression of high molecular weight caldesmon during phenotypic modula-
tion of smooth muscle cells. Proc Natl Acad Sci USA 1987; tion of smooth

9 Richman PI, Tilly R, Jass JR, et al. Colonic pericryptal sheath cells: characterization of cell type with new meath cells: characterization of cell type with new
monoclonal antibodies. F Clin Pathol 1987;40:593-600. 